\title{
CRISPR/Cas9-mediated Editing of Human $\beta$-globin Gene in Human Cells: A Commentary on the Research Ethics
}

\author{
Norman K. Swazo, Ph.D., M.H.S.A. \\ Department of History and Philosophy \\ North South University \\ Bashundhara R/A 1229, Dhaka, Bangladesh \\ Email: norman.swazo@northsouth.edu
}

\begin{abstract}
Recently, Chinese researchers published the results of their research using a gene-editing technology on abnormal human zygotes. The research team believes this research has prospective clinical application, viz., for gene therapy for $\beta$-thalassemia, a white blood cell disorder, and plan to persist with further studies, despite technical problems in this experiment. The research has elicited international criticism from both scientific and bioethics domains, because it innovates beyond the current global consensus against human germ line modification. This paper comments on some ethical issues presented by the research report and concludes that, under present circumstances, the Chinese research team did not meet a standard of scientific responsibility.
\end{abstract}

Keywords: CRISPR/Cas9; human germ line modification; ethics; China; gene-editing technology

Reporting: On 01 April 2015, Chinese researchers Puping Liang et al. (from the Guangdong Province Key Laboratory of Reproductive Medicine, Sun Yat-sen University), published a research article in the Journal Protein \& Cell, reporting the results of an experiment using a gene-editing tool known as CRISPR/Cas9 (clustered regularly interspaced short palindromic repeats/Cas9, the "editing" enzyme) ${ }^{1}$. This experiment used polyspermic human zygotes, specifically tripronuclear (3PN) zygotes (i.e., zygotes having one oocyte nucleus and two sperm nuclei) that are not viable for human reproduction and which are, therefore, discarded during in vitro fertilization (IVF). The authors in this case pursued their research opining that, 3PN zygotes provide "an ideal model system to examine the targeting efficiency and off-target effects of [the] CRISPR/Cas-9 [gene editing tool used] during early human embryonic development." The scientific team here is concerned with eventual therapeutic application of the technology for treatment of $\beta$-thalassemia, a disease that involves mutations of the $\beta$-globin gene. The therapeutic task is to "repair" the mutation with gene-editing techniques, hence the choice here of CRISPR/Cas9 for that purpose.

The results of the experiment showed 28 of 54 embryos cleaved by the Cas 9 enzyme ( $52 \%$ efficiency). The genetically edited embryos were "mosaic"-the significance of which is that "it would be impossible to predict gene editing outcomes through pre-implantation genetic diagnosis (PGD)." There were also "notable off-target effects." The research team estimated an editing efficiency of $25 \%$, then cautioned that the "high rate of repair using endogenous sequences presents obvious obstacles to gene therapy strategies using CRISPR/Cas9," i.e., "unwanted mutations" being the most obvious. The authors interpret the results to mean that there is need for "further investigation of the molecular mechanisms of CRISPR/Cas9-mediated gene editing in human model." The most important cautionary note here is that the "off-target effect of CRISPR/Cas9 should be investigated thoroughly before any clinical application." 
In a section of the paper entitled, "Compliance with Ethics Guidelines," the authors declare that the study (1) "conformed to ethical standards of the Helsinki Declaration, (2) "was approved by the Medical Ethical Committee" of the affiliate hospital, and (3) the 3PN zygotes were donated with "signed informed consent forms." Informed consent and human subjects (IRB) review are standard requirements for this kind of research, of course. The Helsinki Declaration, revised most recently in October 2013, addresses human subjects research and, pertinent to this experiment, "research on identifiable human material" ${ }^{2}$. Thus, the authors signal their responsibility relative to "applicable international norms and standards," including "generally accepted scientific principles." In this sense, then, it would seem the research conducted here is not prohibited either by extant applicable international norms and standards or by any applicable generally accepted scientific principles.

Discussion: Notwithstanding, the foregoing summary of experimental results raises any number of ethical questions. The most important concerns the fact that the research team decided to use human embryos, albeit IVF-discarded abnormal polyspermic zygotes. Citing earlier experimental work, the authors recognize there has been "great progress in understanding the utilization of CRISPR/Cas9 in a variety of model organisms," in which case it is clear that current research designs can investigate the molecular mechanism of CRISPR/Cas9 and progress adequately when undertaken in model organisms other than human embryos ${ }^{3}$. The latter point is significant in view of ethically grounded caution about human germline modification that can occur through genetic manipulation of human zygotes.

For example, anticipating this publication from the Chinese team, a number of researchers published their perspective in the Journal Science on 19 March 2015, recommending appropriate caution because "CRISPR/Cas9.... can be used to change the DNA in the nuclei of reproductive cells that transmit information from one generation to the next (an organism's 'germ line')," thus because of "unknown risks to human health and well-being" that are consequent to germ line modification ${ }^{4}$. The caution pronounced by this group is grounded on known results from in vivo research (using mice and monkeys).

The authors of the Science paper are correct to point to a fundamental question that requires some answer prior to proceeding with the use of such technology in human models-even if such models are abnormal 3PN zygotes: Is the treatment or cure of severe disease in humans (e.g., $\beta$-thalassemia, for which the Chinese team anticipated prospective application of the CRISPR/Cas9 technology) a responsible use of genome engineering? If so, under what circumstances is the use of this technology responsible (e.g., those circumstances clinically identifiable for a disease such as $\beta$-thalassemia)? By proceeding with their research design, the Chinese team presumes that use of this technology for a disease like $\beta$-thalassemia is a morally responsible use. But it is not clear that one can argue defensibly that once the technique's efficiency is assured, with the risk of off-target mutations reduced measurably or predictably, one can move to clinical application. That presumption is not morally warranted as long as non-human animal models are available for testing the molecular mechanism of the technology, especially since it is also unclear, as the Science authors warn, that there may be "on-target events that have unintended consequences" 5 . Thus, the recommendation to discourage germ line modification research is indeed morally compelling, thus making any continued research involving abnormal human zygotes as used by the Chinese team prohibitive for the time being.

Another group, publishing in Nature on 12 March 2015, argued that, given "unpredictable effects on future generations" that follow from use of "genome editing in human embryos using current technologies," not to mention that this type of research "could be exploited for non-therapeutic modifications," therefore this research is "ethically unacceptable" ${ }^{6}$. So long as there are other non-human organisms that can serve as effective models for this kind of research, it is generally thought that there is no scientific or moral warrant for use of such geneediting technology on human embryos. Thus, the appeal is to (a) generally accepted scientific principles, (b) the 
current standard of research in animal models such as mice, rats, monkeys, cattle, sheep, and pigs, as well as to (c) morally relevant assessments of benefit (safety, efficiency) and risk (unintended and unpredictable adverse harm from on-target editing and off-target mutations). The Chinese research clearly ventured beyond currently accepted research models, these models providing the responsible-use "paradigm" according to which researchers demonstrate their compliance with internationally sanctioned norms. As the Nature authors write, "All techniques currently in various stages of clinical development focus on modifying the genetic material of somatic cells, such as T cells (a type of white blood cell)"-thus, not human reproductive cells (i.e., "germ" cellssperm and ova) [italics added]. The Chinese "innovation" ventures well beyond currently permissible research even for the disease of concern, e.g., intravenous transfusion of modified $T$ cells in patients having $\beta$ thalassemia.

The publication has prompted numerous scientific and ethical commentaries from the public at large. The Center for Genetics and Society (a prominent public interest advocacy organization in the USA) calls for strengthened global policies designed to constrain and restrain germ line modification. The Center's Executive Director underscores the central concern: "No researcher has the moral warrant to flout the globally widespread policy agreement against altering the human germline" ${ }^{7}$.

This opinion is supported independently, given the statement on germ line genome modification issued by the International Society for Stem Cell Research, dated 15 March 2015, which "calls for a moratorium on attempts at clinical application of nuclear genome editing of the human germ line to enable more extensive scientific analysis of the potential risks of genome editing and broader public discussion of the societal and ethical implications" ${ }^{8}$. So long as properly regulated gene-editing research can be done in human somatic tissues, there is no need for basic research on human germ cells, thus allowing appropriate opportunity for public deliberation about the ethical, legal, and social implications of such technology.

Similarly, the Council for Responsible Genetics has issued its position paper on human germ line manipulation, acknowledging that, "Given what has been accomplished in animals and the availability of in vitro fertilization, there appear to be no technical obstacles to initiating germ line modification experiments in humans" ${ }^{9}$. But, the Council "strongly opposes the use of germline gene modification in humans," based on "scientific, ethical, and social concerns"- the "scientific," including inefficiency of techniques used in mammals, unintended adverse harm observed in mouse models (e.g., mice lacking eyes, lacking "the semicircular canals of their inner ears"), and, yet more problematic, "developmental disruptions in the manipulated embryo itself;" the "ethical," including the fact that foregoing pregnancy, prenatal genetic diagnosis, abortion, and adoption are morally defensible options; "social," in the sense of identifying and implementing relevant social measures that are enabling, short of genetic enhancement.

At issue in the foregoing discussions is a concern for scientific integrity in such research and thus what a report published by the American Association for the Advancement of Science (AAAS) in the year 2000 called "balancing scientific freedom and responsibility" ${ }^{10}$. It is important to note here that public "policy" is generally regulatory oversight that does not entail "proscription" in the sense of an "explicit ban," in which case governmental regulatory authorities are free to alter the current global consensus against human germ line modification. In the case of China, the government's "Guidelines on Human Assisted Reproductive Technologies" (2003) prohibit using "human egg plasma and nucleus transfer technology for the purpose of reproduction, and manipulation of the gene in human gamete, zygote, or embryo for the purpose of reproduction" ${ }^{\prime 1}$. The Chinese research team can argue that they have been compliant with national policy. However, as Frankel and Chapman argue, "To act responsibly... with respect to IGM [inheritable genetic modifications] means not engaging in such 
research until public regulatory mechanisms are in place to review proposals, while also supporting educational efforts to help scientists and the public to consider the broader implications of the research" ${ }^{12}$.

Conclusion: Clearly, the question about public regulatory mechanisms is not a matter to be governed only by national guidelines, even if the research is not directed towards human reproduction as such. It is research that must be responsive to global policy concerns about human germ line modification, precisely because this is a transnationally human interest that is not contained by sovereign political right or nationally derived public policy. The Chinese researchers have not exercised their scientific freedom according to this concept of responsibility, in which case one can only conclude that this particular research should not have been done at this particular time.

\section{References:}

1. Liang P, Xu Y, Zhang X, Ding C, Huang R, Zhang Z, Lv J, Xie X, Chen Y, Li Y, Sun Y, Bai Y, Songyang Z, Ma W, Zhou C, Huang J. CRISPR/Cas9-mediated Gene Editing in Human Tripronuclear Zygotes. Protein \& Cell, 2015. 18 April. DOI: 10.1007/s13238-015-0153-5.

2. World Medical Association. Ethical Principles for Medical Research Involving Human Subjects, $64^{\text {th }}$ WMA General Assembly, October 2013. http://www.wma.net/en/30publications/10policies/b3/, accessed 26 April 2015.

3. Liang P, Xu Y, Zhang X, Ding C, Huang R, Zhang Z, Lv J, Xie X, Chen Y, Li Y, Sun Y, Bai Y, Songyang Z, Ma W, Zhou C, Huang J. CRISPR/Cas9-mediated Gene Editing in Human Tripronuclear Zygotes. Protein \& Cell, 2015. 18 April. DOI: 10.1007/s13238-015-0153-5.

4. Baltimore D, Berg P, Botchan M, Carroll D, Charo RA, Church G, Corn JE, Daley GQ, Doudna JA, Fenner M, Greely HT, Jinek M, Martin GS, Penhoet E, Puck J, Sternberg SH, Weismann JS, Yamamoto KR. A prudent path forward for genomic engineering and germline modification. Science, 2015; 348(6230):36-38. http://www.sciencemag.org/content/348/6230/36; accessed 26 April 2015.

5. Baltimore D, Berg P, Botchan M, Carroll D, Charo RA, Church G, Corn JE, Daley GQ, Doudna JA, Fenner M, Greely HT, Jinek M, Martin GS, Penhoet E, Puck J, Sternberg SH, Weismann JS, Yamamoto KR. A prudent path forward for genomic engineering and germline modification. Science, 2015; 348(6230):36-38. http://www.sciencemag.org/content/348/6230/36; accessed 26 April 2015.

6. Lanphier E, Urnov F, Haecker SE, Werner M, Smolenski J. Don't Edit the Human Germ Line, Nature, 12 March 2015. http://www.nature.com/news/don't-edit-the-human-germ-line-1.17111; accessed 26 April 2015.

7. Center for Genetics and Society, Public interest group calls for strengthening global policies against human germline modification [press statement], 22 April 2015, http://www.geneticsandsociety.org/article.php?id=8528; accessed 26 April 2015.

8. International Society for Stem Cell Research, The ISSCR Statement on Human Germline Genome Modification, 19 March 2015, http://www.isscr.org/statement-on-human-germline-genome-modification, accessed 26 April 2015.

9. Council for Responsible Genetics, Position Paper on Human Germline Modification, 2001, http://www.councilforresponsiblegenetics.org/ViewPage.aspx?pageld=101; accessed 26 April 2015.

10. Frankel, M.S., Chapman, A.R., Human Inheritable Genetic Modifications: Assessing Scientific, Ethical, Religious, and Policy Issues, American Association for the Advancement of Science, September 2000; http://www.aaas.org/sites/default/files/migrate/uploads/germline.pdf 
11. Ishii, T. Potential impact of human mitochondrial replacement on global policy regarding germline gene modification. 2014, Reproductive BioMedicine Online, 2014, 29:150-155; http:dx.doi.org/10.1016/j.rbmo.2014.04.001; accessed 26 April 2015.

12. Frankel, M.S., Chapman, A.R., Human Inheritable Genetic Modifications: Assessing Scientific, Ethical, Religious, and Policy Issues, American Association for the Advancement of Science, September 2000; http://www.aaas.org/sites/default/files/migrate/uploads/germline.pdf

Conflict of interest: No conflict of interest to report. 